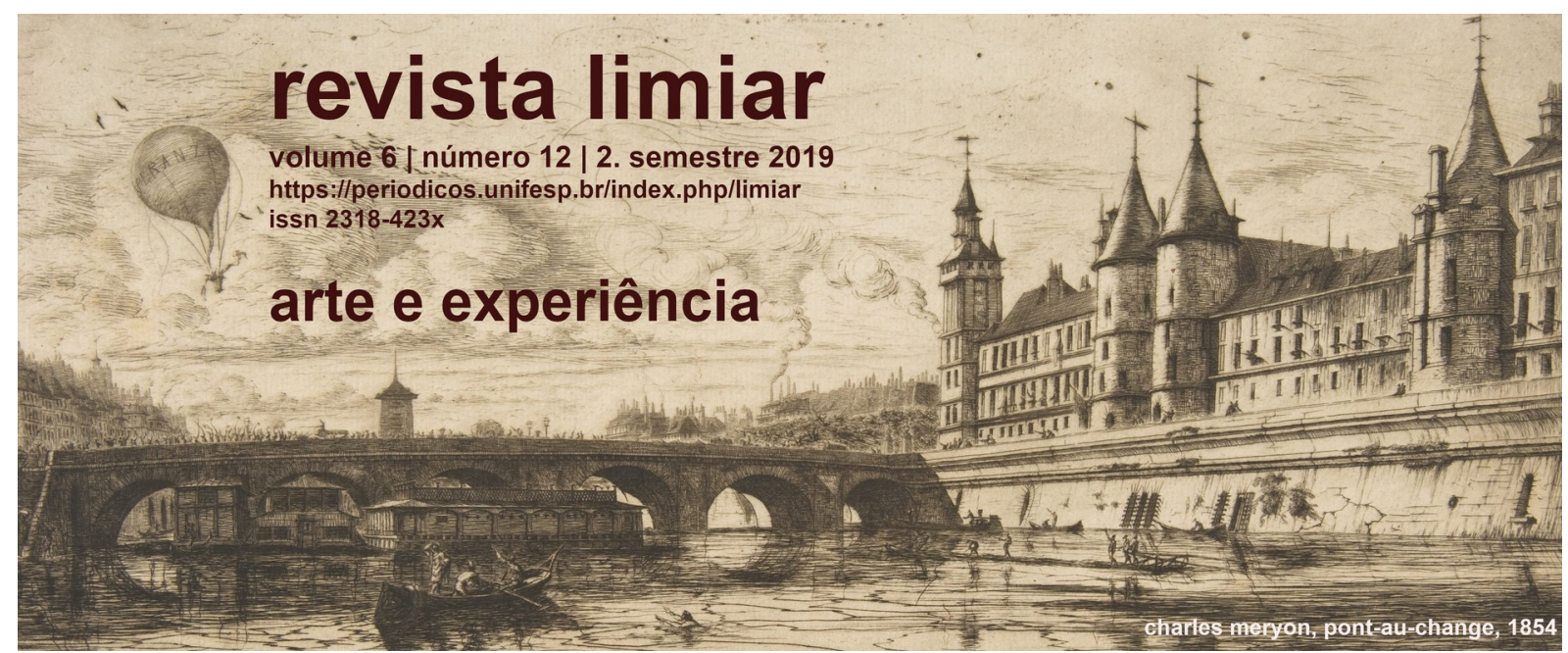

\title{
Uso mercantilizado do belo e o sublime: notas sobre Imitação da vida (2013), de Mathias Poledna
}

\section{Eduardo Socha*}

Resumo: $O$ ensaio procura apresentar inicialmente as condições materiais que, segundo a interpretação de Fredric Jameson, propiciaram a transição, a partir do final dos anos 1960, de uma estética do sublime para uma estética funcional do belo como orientação dominante da produção artística. Em seguida, expõe aspectos da analítica kantiana do sublime que vinculam o sublime à concepção do moderno. Por fim, verifica a tensão entre a situação descrita por Jameson e o sublime kantiano a partir de considerações sobre a instalação Imitation of life, de Mathias Poledna, a única obra apresentada no pavilhão austríaco da Bienal de Veneza de 2013.

Palavras chave: Sublime - Modernismo - Mathias Poledna - Fredric Jameson

\begin{abstract}
This essay discusses the material conditions that, according to Fredric Jameson, moved forwards the transition from an aesthetics of the sublime to a functional and simulacral aesthetics of the beautiful as the dominant orientation of artistic production from the late 1960s. The essay sums up the Kantian analysis of the sublime and the connection of the sublime to the conception of modernism. Finally, it verifies the tension between the situation described by Jameson and the sublime, through an analysis of Mathias Poledna's "Imitation of Life", the only artwork showed in the Austrian pavilion at the 55th Venice Biennale.
\end{abstract}

Keywords: Sublime - Modernism - Mathias Poledna - Fredric Jameson

\footnotetext{
* Doutor em filosofia pela USP. E-mail para contato: esocha@gmail.com.
} 


\section{Introdução}

Se aceitarmos a periodização de Fredric Jameson, indicada em "Fim da arte" ou "fim da história"?, o "estilo do sublime" - expressão que consubstanciaria, grosso modo, o impulso modernista nas diferentes linguagens artísticas a partir do século 19 - teria se esgotado no final dos anos 1960, mediante a "dissolução da vocação artística de atingir o absoluto" ${ }^{\prime}$. No esquema de Jameson (que segue em parte, como reconhece o próprio autor, a terceira crítica kantiana e a estética hegeliana), haveria apenas dois regimes de codificação estética: o "estilo do belo" e o "estilo do sublime". O esquema, de fato, nada tem de original e evoca sem grandes alterações a terminologia do debate estético corrente já no séc. 18 (pelo menos, desde Edmund Burke). Contudo, o ponto interessante no esquema de Jameson estaria na interpretação que oferece a respeito da conhecida sentença hegeliana sobre o "fim da arte", uma interpretação estabelecida a partir das categorias do belo e do sublime. Segundo o autor, deveríamos compreender o "fim da arte" hegeliano como uma espécie de aquiescência teórica segundo a qual o regime de codificação compreendido como "estilo do belo", destinada a propiciar (em termos kantianos) o acordo entre a faculdade de imaginação e o entendimento, não seria mais adequado para a apreensão e representação histórica do absoluto. Para Jameson, uma "arte do sublime" (que posterioremente se reconheceria como estética modernista), viria suplantar o lugar da "arte do belo" como forma de consciência adequada à revelação da verdade histórica do espírito. Hegel estava parcialmente correto em constatar o "fim da arte", na medida em que o "estilo do belo" havia deixado de ser, sobretudo a partir da arte romântica, o modo mais elevado no qual a verdade produz historicamente uma existência para si. No entanto, por permanecer conceitualmente vinculado a um regime de codificação específico, o prognóstico de Hegel estaria marcado, segundo Jameson, por um equívoco. Pois do fim de uma certa arte não se seguiria, conforme a progressão triádica do espírito objetivo, a supressão da arte pela filosofia. O "fim da arte" indicado por Hegel corresponderia, na verdade, à transição da predominância de um regime de codificação estética a outro, a passagem histórica de uma "arte do belo" para uma "arte do sublime". Nesse contexto, o sublime designaria simplesmente aquela concepção compreendida como a própria negação determinada do conceito hegeliano de arte, uma concepção marcada pelo progressivo afastamento da arte 1 JAMESON, "Fim da arte" ou "fim da história" ? In: A cultura do dinheiro, Petrópolis: Vozes, 2001, p. 85. 
de suas funções sociais heterônomas. Designaria o modo de formalização caracterizado por um impulso "puramente negativo", em busca do incomensurável e do absoluto, impulso dado pelo encapsulamento formal das linguagens artísticas sobre si mesmas; impulso que, nas poéticas do modernismo, estariam destinadas a questionar constantemente as convenções formais de seu próprio meio.

Entretanto, no final dos anos 1960, estaríamos presenciando (ainda de acordo com o esquema de Jameson) um "segundo fim da arte", desta vez o fim da estética do sublime. A emergência de manifestações como os happenings e as inovações teatrais de Beckett e Grotowski sinalizariam o esgotamento das pretensões do esteticismo modernista no sentido de produzir absolutamente uma "existência para si". Dito de outro modo, o desfecho de uma era da "arte do sublime" ficaria evidenciado na obsolescência da ideia de autonomia nas diferentes linguagens e meios artísticos, no esgotamento de uma prática artística dissociada de fins exteriores, própria ao modernismo. Jameson evita profilaticamente a condenação moralizante do estágio da produção cultural que sucede a tal desfecho. Limita-se a indicar que, após o colapso do modernismo e da "estética do sublime", a produção cultural desaguaria necessariamente na caldeira fragmentária do pós-moderno. Assistiríamos então, no pós-modernismo, a um retorno progressivo do belo como dominante cultural, mas de um belo orientado à pura gratificação sensorial, ao consumo cultural extravagante, ao kitsch, isto é, a um belo funcional, que não se pretende mais efetivamente artístico e que se encontra destituído da procura pelo absoluto de uma verdade - ao contrário do belo de inspiração idealista que se compreendia como absoluto histórico. $\mathrm{Na}$ arte contemporânea, o sublime teria perdido sua validade e sua produtividade crítica - o modernismo, como capítulo decisivo na história da arte, estaria encerrado.

A fim de examinar a pertinência dessa exaustão da ideia de sublime na arte contemporânea, conforme sugerida na periodização de Jameson, propõe-se neste ensaio três momentos argumentativos distintos, cujos propósitos resumidamente seriam: 1) expor as condições materiais que, segundo a interpretação de Jameson, provocariam a segunda transição, a partir do final dos anos 1960, de uma estética do sublime para um belo mercantilizado como dominante cultural de produção artística; 2) examinar aspectos da recepção da analítica kantiana do sublime que associaram o sublime à concepção do moderno; 3) verificar a tensão entre o pós-moderno descrito por Jameson e o sublime kantiano, a partir de uma breve análise da instalação Imitation of life, de Mathias Poledna, obra que representou o pavilhão austríaco da Bienal de Veneza de 2013. 
1.

Em linhas gerais, podemos dizer que o trabalho de Fredric Jameson procura oferecer uma avaliação materialista sobre o deslocamento da função social da arte a partir da década de 1970, deslocamento que convenciona denominar pós-modernismo. Não se pretende realizar aqui o recenseamento das teorias às quais Jameson faz alusão, nem aprofundar a discussão sobre a trajetória e validade do conceito, que, segundo o próprio autor, virou bestseller de uma lexicologia da mídia. Convém, entretanto, esboçar uma definição genérica que o autor fornece ao termo. O pós-modernismo, compreendido como a dominante cultural de uma modificação sistêmica da base econômica, não constituiria a formalização de um estilo específico (ou conjunto de estilemas tradicionalmente indicado por um "-ismo"). Seria antes, para Jameson, um conceito materialista que daria visibilidade ao entrelaçamento de dois processos históricos, um de ordem econômica, outro de ordem estética:

a) no plano econômico, a transição de um estágio industrial do capitalismo para o estágio de intensa financeirização, aliada a novas formas de interrelação dos media. Tal estágio - descrito por Ernest Mandel como "capitalismo tardio"2 - seria caracterizado, por um lado, pela saturação da produção industrial e pela ampliação do setor de serviços, pela transferência dos meios de produção para países periféricos, pelo aumento do fluxo internacional de capital e, por outro lado, pela intensificação do desenvolvimento tecnológico das formas de comunicação de massa. Tal transformação significativa na base econômica comprometeria a própria distinção entre infraestrutura e superestrutura ideológica, na medida em que a "cultura" (através da fusão institucionalizada com a tecnologia pelos media) passaria a agenciar setores primordiais da base econômica. Com isso, a própria esfera da circulação de bens culturais é modificada. Segundo Jameson, a absorção integral das obras de arte à forma-mercadoria, mesmo da arte mais avançada, demandaria, portanto, o tratamento dos fenômenos culturais em termos de economia política.

b) no plano estético, o desgaste da evolução das diferentes linguagens artísticas, após terem atingido os limites formais de seus suportes, e a consequente absorção do impulso modernista pela cultura oficial. Jameson observa certa canonização do

2 A expressão "capitalismo tardio" também é utilizada pela Escola de Frankfurt como sinônimo de "sociedade administrada", mas neste caso se refere ainda a um estágio marcado pela centralidade da produção industrial, pelo "aumento do controle burocrático (...) e interpenetração do governo e do capital monopolista". Cf. JAMESON, Pós-modernismo. A lógica cultural do capitalismo tardio, São Paulo: Ática, 2006, p. 22-3. 
modernismo - que seria visível, por exemplo, tanto nas cópias decorativas de Kandinsky e Pollock penduradas nas paredes dos escritórios de empresas multinacionais, quanto na celebração de Kafka, Godard e Stockhausen ${ }^{3}$. Tal institucionalização do modernismo, acentuada a partir dos anos 60, teria domesticado a disposição utópica de transgressão de valores naturalizados da estrutura simbólica social, isto é, teria domesticado o impulso puramente negativo do sublime estético. O modernismo, perdendo seu momento de negatividade, aliava-se a novas formas de consumo e styling, de subversão cool adaptadas ao crescente repertório publicitário. Se "Joyce e Picasso não são mais estranhos e repulsivos e

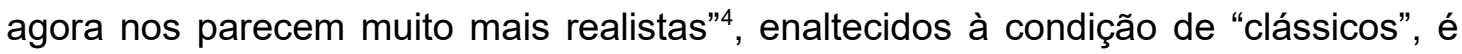
porque tanto novas modalidades de consumo quanto o esgotamento crítico da estética modernista teriam arruinado sua pretensão de construir uma sensibilidade social emancipada por meio da obra de arte, tal como explicitamente preconizavam, de resto, as vanguardas heroicas do início do século 20. O "triunfo comercial" do modernismo significava, portanto, sua derrota como projeto. O declínio de seu potencial emancipatório, a "perda de tensão da arte construtiva" e a consequente mudança da função social da arte contemporânea solicitariam a compreensão dos fenômenos artísticos sob novas coordenadas ${ }^{5}$.

Embora as dimensões econômica e artística se fundem no conceito de pósmodernismo, valeria discutir, tendo em vista o propósito deste ensaio, apenas a segunda dimensão, a exaustão do impulso modernista ${ }^{6}$. Para Jameson, o distanciamento crítico e

\footnotetext{
3 Notemos que Adorno estava ciente de tal fenômeno no início dos anos 1960: "A falsa reconciliação abre caminho até mesmo para pintura radicalmente abstrata: até a arte não-figurativa presta-se à decoração mural do novo bem-estar" (ADORNO, Teoria estética, Lisboa: Edições 70, 2008, p. 345).

4 JAMESON, A virada cultural - reflexões sobre o pós-modernismo, p. 42. Trad. Carolina Araújo. Civilização Brasileira, 2006.

5 Embora em contexto distinto, o diagnóstico é partilhado por Otília Arantes e Paulo Arantes, quando afirmam que o procedimento crítico e modernista por excelência, o princípio da construção, reverte-se em ideologia na hora histórica em que se realiza: "A perda de tensão da arte construtiva não advém de uma fraqueza, mas do próprio ímpeto construtivo, vitimado pela contradição que o anima" (ARANTES; ARANTES, Um ponto cego no projeto moderno de Jürgen Habermas, São Paulo: Brasiliense, 1995, p. 65).

6 Antes de o pós-modernismo se tornar moeda conceitual comum da crítica especializada (e não especializada), Peter Bürger indicava, em 1974, o colapso das categorias de "novo" e de "autonomia"; portanto, do "estilo do sublime" - e observava o retorno cada vez mais pronunciado da arte à "práxis vital". Esse colapso, que se traduzia pelo oximoro de uma "tradição de rupturas com a tradição", específicos dos movimentos de vanguarda, mostrava que a noção moderna de autonomia correspondia a uma categoria ideológica e histórica da sociedade burguesa; ideológica ao congregar um momento de verdade (momento histórico de rupturas, de negatividade, de separação concreta da arte em relação à práxis vital) e um momento de não-verdade (a hipóstase da categoria de autonomia como "essência" da arte, a pretensão de que autonomia da arte seria valor universal e não um valor social e historicamente condicionado). Também para Bürger, a disponibilidade sincrônica de técnicas e procedimentos artísticos anteriores impedia que um movimento artístico qualquer pudesse "alimentar a
} 
autônomo, que permitia ao modernismo colocar-se acima do existente para capturar a "novidade", não deixaria totalmente de existir a partir dos anos 1970, mas teria sido encoberto no horizonte mais amplo da produção e do consumo de obras pós-modernas. Vale ressaltar também que o autor não prescreve posicionamentos do tipo "contra ou a favor" ao pós-modernismo. Não exorta resistências programáticas a essa lógica cultural do capitalismo tardio - ao contrário, por exemplo, de Habermas, em sua notória defesa do potencial emancipatório ainda não realizado pela modernidade, implicando com isso um horizonte normativo de ação ${ }^{7}$. Mas também não aceita a adesão entusiasta ao pósmoderno. Na visão de Jameson, tanto a crítica frontalmente indignada, de teor moralista, não-dialética, quanto a celebração complacente do pós-moderno envolveriam um "erro categorial"8.

Nesse momento histórico em que o pós-modernismo se converte no modo hegemônico de circulação cultural, Jameson constata, por sua vez, dois elementos constitutivos de criação das obras de arte: 1) o uso do pastiche como dispositivo de neutralização crítica e 2) a dispersão alucinatória de imagens, processo que se assemelharia à descrição nosográfica da esquizofrenia ${ }^{9}$. Quanto ao pastiche, Jameson adianta uma diferença em relação à paródia. Se a paródia consiste na emulação de uma linguagem individual ou idiossincrática com a intenção de ridicularizar seus momentos estilísticos internos, trata-se de um procedimento adequado à negatividade modernista, na medida em que há o reconhecimento implícito de um regime normativo em curso, contra o qual então o procedimento se insurge como crítica ou denúncia. Já a prática do pastiche ignora toda pretensão normativa de uma linguagem ou estilo. No pastiche, não haveria um pressuposto a ser criticado, negado ou superado; linguagens e estilos são nivelados historicamente, e como tal, destituídos em seu potencial crítico. O pastiche pressupõe apenas a disponibilidade sincrônica de formas e estilos do passado. Seria a mera imitação de formas historicamente ultrapassadas, mera pilhagem de diferentes estilos, de maneira a levar à diluição mesma da fronteira entre alta cultura e cultura de massas. Descartando as

pretensão de, como arte, achar-se historicamente mais avançado que outros movimentos" (BÜRGER, Teoria da vanguarda, São Paulo: Cosac Naify, 2008, p. 101; p. 132).

7 Cf. HABERMAS, O discurso filosófico da modernidade, São Paulo: Martins Fontes, 2000.

8 JAMESON, Pós-modernismo. A lógica cultural do capitalismo tardio, p. 73: "(..) pós-modernismo é fenômeno histórico, a tentativa de conceituá-lo em termos de moral tem que ser identificada como erro categorial". Ver também ANDERSON, Perry, Origens da pós-modernidade, Trad. Marcus Penchel, Rio de Janeiro: Zahar, 1999, p. 78: "Isso vedava respostas maniqueístas ao pós-moderno (...) (Para Jameson), o agente coletivo necessário para confrontar essa desordem ainda não existia, mas uma condição para seu surgimento era a capacidade de compreendê-la por dentro".

9 JAMESON, A virada cultural - reflexões sobre o pós-modernismo, p. 20. E também JAMESON, PósModernismo, a lógica cultural do capitalismo tardio, Cap. 1, pp 44-5; 
pretensões de autonomia do modernismo, por meio dessa indiferença histórica e dessa espoliação de diferentes estilos do passado, a figura do pastiche daria visibilidade, portanto, ao processos de fragilização dos próprios conceitos de autoria e de subjetividade modernistas.

A segunda característica fundamental da produção artística correlata ao pósmodernismo consiste naquilo que Jameson qualifica como "esquizofrenia". Grosso modo, essa noção indica a desordem estrutural de uma linguagem qualquer, um distúrbio na relação interna entre seus significantes. A deficiência no estabelecimento de cadeias de significação leva à supressão do "efeito-de-sentido" e à retenção do sentido literal do significante. Para Jameson, na medida em que a experiência da temporalidade seria um efeito da linguagem, uma das consequências da esquizofrenia seria a incapacidade de se articular passado, presente e futuro; na esquizofrenia, ocorreria a redução "da experiência dos puros significantes materiais a uma série de puros presentes, não relacionados no tempo"10. Jameson transpõe tal descrição para o âmbito da estética e considera que as obras artísticas, após o fim do modernismo, seriam marcadas por um excesso alucinatório de imagens, de pouca espessura narrativa - uma valorização de elementos puramente sensoriais, portadores de um belo que não estabelece mais qualquer pretensão espiritual. Essa saturação de significantes prejudica a formação de uma sequência coerente entre momentos do passado. Assim como no pastiche, a esquizofrenia reduziria então o tempo da experiência subjetiva a uma série de instantes neutralizados, dados em uma espécie de "presente perpétuo" e, consequentemente, estabeleceria um "relaxamento à lógica da história".

Em resumo, pastiche e esquizofrenia seriam os elementos constitutivos do pósmoderno, na qual "a própria cultura se torna um produto, e o mercado seu próprio substituto". Jameson afirma que, no campo da produção artística, "o pós-modernismo é o que se tem quando o processo de modernização está completo", quando a potência transgressora do modernismo se esgota ${ }^{11}$. É desse modo que o fim da era do "estilo do sublime" representa um "segundo fim da arte"12. Haveria, na estilização pós-moderna do kitsch, o retorno do "estilo do belo", desta vez destituído, como vimos, das pretensões idealistas de atingir o absoluto. A fim de avaliar a pertinência teórica desse "segundo fim da arte", convém retomar brevemente a analítica kantiana do sublime, na medida em que

10 JAMESON, Pós-modernismo. A lógica cultural do capitalismo tardio, p. 53.

11 Ibid., p. 13.

12 JAMESON, "Fim da arte" ou "fim da história" ?, p. 85. 
forneceria a base conceitual para a aproximação entre sublime e o moderno no modelo proposto por Jameson.

\section{2.}

Encontramos, de fato, na Crítica da faculdade de julgar de Kant, a matriz teórica que levaria autores de tradições distintas a considerar o sentimento do sublime como critério decisivo para a reflexão filosófica mais abrangente sobre a arte moderna posterior, sobretudo em função do caráter de autonomia ${ }^{13}$. Conforme a terceira crítica, o sublime (matematicamente considerado) resultaria do conflito entre a faculdade da imaginação e a exigência da faculdade da razão por uma representação absoluta da totalidade ${ }^{14}$. $O$ sentimento do sublime seria "aquilo em comparação com o qual tudo o mais é pequeno"15, o absolutamente grande, provocado por objetos da natureza. O sublime não está contido na forma sensível, mas nas ideias subjetivas da razão. Assim, ao contrário do belo, o sublime reside na subjetividade que comporta as ideias de infinitude e de totalidade. A faculdade da imaginação, diante da necessidade de fornecer uma representação conveniente do objeto natural "absolutamente grande", falha em seu "ato de dar forma", ou seja, revela-se inadequada para avaliar tal grandeza. Isso porque, no livre jogo das faculdades, a razão requer a compreensão (Zusammenfassung, representação completa, única) e não a mera apreensão (Auffassung, temporal, sucessiva) da totalidade desse objeto, uma solicitação que não é cumprida pela faculdade da imaginação. Quando considerado dinamicamente, o ajuizamento do sublime provoca a sensação de desprazer, medo e terror, na medida em que a força e o poder de tais objetos da natureza são o índice da insignificância da capacidade do sujeito de resistir a eles. Contudo, é precisamente nessa falha que o sujeito descobre as capacidades superiores da faculdade da razão. O desprazer que se dá no plano da sensibilidade atesta a limitação das capacidades de representação da imaginação, mas indica também a força ilimitada das ideias da razão. Ou seja, na medida em que as ideias de infinitude e totalidade absoluta podem ser pensadas, ainda que não determinadas (já que a sensibilidade não é constitutiva para tais ideias), a razão revela-se como faculdade superior à própria magnitude indiciada pelos objetos da natureza que provocam o sentimento do sublime. Embora a imaginação descubra sua incapacidade de representar o

13 Ou seja, tal consideração não se limita a Jameson, mas é tomada como evidente por autores de tradições tão distintas quanto Lyotard e Adorno. Um bom recenseamento dessa influência no debate contemporâneo está no posfácio redigido por Pedro Sussekind para o ensaio de Schiller sobre o sublime, recentemente publicado em portugûes. Cf. SCHILLER, Do sublime ao trágico, Belo Horizonte: Autêntica, 2016.

14 Cf. KANT, Crítica da faculdade do juízo, Rio de Janeiro: Forense Universitária, 2008, parag. 23-29.

15 Ibid., p. 96. 
indeterminado, ela encontra na razão sua insuficiência e, portanto, o suprassensível racional como fonte de sua própria determinação (Bestimmung). Dito de outro modo, o sublime kantiano é um sentimento do espírito que rompe o acordo entre imaginação e razão, a harmonia que estava assegurada no ajuizamento do belo, e permite afirmar a superioridade da razão em relação à natureza, colocando-a diante de um absoluto cujo objeto é a ideia de liberdade ${ }^{16}$.

É verdade que, para Kant, o sentimento do sublime não é provocado por obras de arte, mas por objetos da natureza. Mais do que isso, conforme a analítica do sublime, não existem objetos propriamente sublimes, mas objetos que suscitam o sentimento e a experiência do sublime - trata-se, afinal, de uma categoria reflexionante, não objetiva. Entretanto, sabemos que pouco após a publicação da terceira crítica, a descrição kantiana do sublime (devedora, por sua vez, da descrição dos ingleses, principalmente Edmund Burke, no séc. 18) já servia de referência para a compreensão de novas modalidades de criação artística, capazes de potencializar esse sentimento. Friedrich Schiller talvez tenha sido o primeiro, na década de 1790 , a transpor a descrição kantiana do sentimento do sublime e de seu ideário correlato - indeterminação, infinitude, irrepresentabilidade do absoluto - para o plano da criação e da percepção artística, das novas possibilidades de experiência estética, inaugurando com isso uma tradição crítica voltada à compreensão moderna de um "estilo do sublime"17. Podemos dizer que a interpretação de Jameson, ligada a essa tradição schilleriana, não estaria muito afastada, por exemplo, das interpretações de Lyotard e Adorno sobre a relevância do sublime para reflexão filosófica da arte moderna ${ }^{18}$.

16 Tendo em vista nosso escopo, a implicação moral referente ao ajuizamento do sublime, fundamental para a crítica kantiana, não será aqui abordada.

17 Ver SCHILLER, Do sublime ao trágico.

18 Como dito, a herança schilleriana de tal transposição se fez perceber, além de Jameson, em autores fundamentais da estética contemporânea, como Lyotard e Adorno. Para Lyotard, "é indispensável voltar à Analítica do sublime da Crítica da Faculdade de Julgar, de Kant, se quisermos ter uma ideia do que está em jogo no modernismo, na vanguarda (...) Desde há um século que as artes não encaram o belo como seu objeto principal mas sim como algo que diz respeito ao sublime" (LYOTARD, O inumano - Considerações sobre o tempo, Lisboa: Editorial Estampa, 1997, p. 139). O teor de tal descrição sobre o sublime kantiano é continuamente reiterado pelo autor; ver, por exemplo, "Este sentimento contraditório, prazer e dor, felicidade e angústia, exaltação e depressão, foi baptizado ou rebaptizado, entre o século XVII e o século XVIII europeus, com o nome de sublime. Foi nesta palavra que se decidiu e perdeu a sorte da poética clássica, foi com este nome que a estética fez valer os seus direitos críticos sobre a arte, e que o romantismo, ou seja o modernismo, triunfou." (Ibid., p. 98). Do mesmo modo, para Adorno, "as obras em que a estrutura estética se transcende sob pressão do teor de verdade ocupam o lugar do que outrora indicava o conceito de sublime (...) $O$ sublime que Kant reservava à natureza tornou-se constituinte da arte" (ADORNO, Teoria estética, p. 297-8). Adorno acredita que "ao longo da modernidade, após o declínio da beleza formal, a ideia de sublime foi a única que restou entre as ideias tradicionais" (Ibid., p. 299), sentença que converge com o propósito central do pensamento de Lyotard. Para esses autores, o modernismo visava quebrar certo acordo entre imaginação e entendimento no plano historicamente determinado da criação e da percepção artísticas. Apesar da herança schilleriana em comum, segundo João Pedro Cachopo, "o modo como Adorno reflete sobre o conceito de sublime distingue-se claramente do de Lyotard, que o adota manifestamente como uma espécie de emblema da sua filosofia." 
Jameson, no entanto, considera que a relevância do sublime se perde no final dos anos 1960 e propicia um "segundo fim da arte". A partir do pós-moderno, no interior do qual passaria então a prevalecer a estilização do kitsch, haveria um retorno meramente funcional da "estética do belo" como regime hegemônico de codificação estética.

A sentença de Jameson é enfática: o "segundo fim da arte" seria consequência da irrelevância das ideias de moderno e sublime. Nesse sentido, não seria infrutífero examinar brevemente uma obra, a nosso ver significativa no campo institucional das artes visuais, denominada Imitação da vida (2013), do austríaco Mathias Poledna. A hipótese aqui é a de que a realização da obra daria indícios de uma nova torção histórica do "estilo do sublime", mas desta vez sob a própria estilização pós-moderna do kitsch.

3.

Imitação da vida era a única obra do pavilhão austríaco na Bienal de Veneza de 2013. No interior do pavilhão, atravessava-se um imenso vestíbulo minimalista, uma espécie de cubo branco que conduzia a uma sala escura de projeção. Na sala, projetava-se um simples desenho animado, feito em $35 \mathrm{~mm}$, de duração de três minutos, continuamente repetido. Não havia cadeiras nem objetos na sala, apenas a projeção daquela animação. vocabulário visual e sonoro era prontamente reconhecível; lembrava os primeiros filmes coloridos da Disney dos anos 1930 e início dos 1940, a linguagem de longa-metragens como Branca de neve, Pinóquio, Dumbo. À maneira pós-moderna de um pastiche, a animação de Poledna utilizava as mesmas texturas, atmosferas e palhetas de cores, os mesmos ritmos e movimentações daqueles produtos culturais que viriam impulsionar a cultura de massas, transformando-se em parte constitutiva do nosso imaginário. Do ponto de vista narrativo, nada de particularmente interessante ou inquietante ocorria na animação: o protagonista, um melancólico jumento vestido de marinheiro, era despertado no meio de uma floresta por um coro de pássaros, e em seguida passava a cantar a música l've Got a Feeling You're Fooling Me (hit dos filmes musicais dos anos 1930) e a ensaiar passos de dança que evocavam o estilo de Fred Astaire. A narrativa mínima e circular parecia encerrar o personagem em uma forma de presente perpétuo, pertencente a um tempo mítico, na qual a simpática melancolia do jumento era cercada pela natureza festiva e cintilante. Em sua aparência ingênua, isenta de qualquer nostalgia, o conteúdo não provocava estranhamento algum no espectador.

(CACHOPO, Verdade e enigma - Ensaio sobre o pensamento estético de Adorno, Lisboa: Edições Vendaval, 2013, p. 352). Ver também o posfácio no mencionado livro de Schiller. 


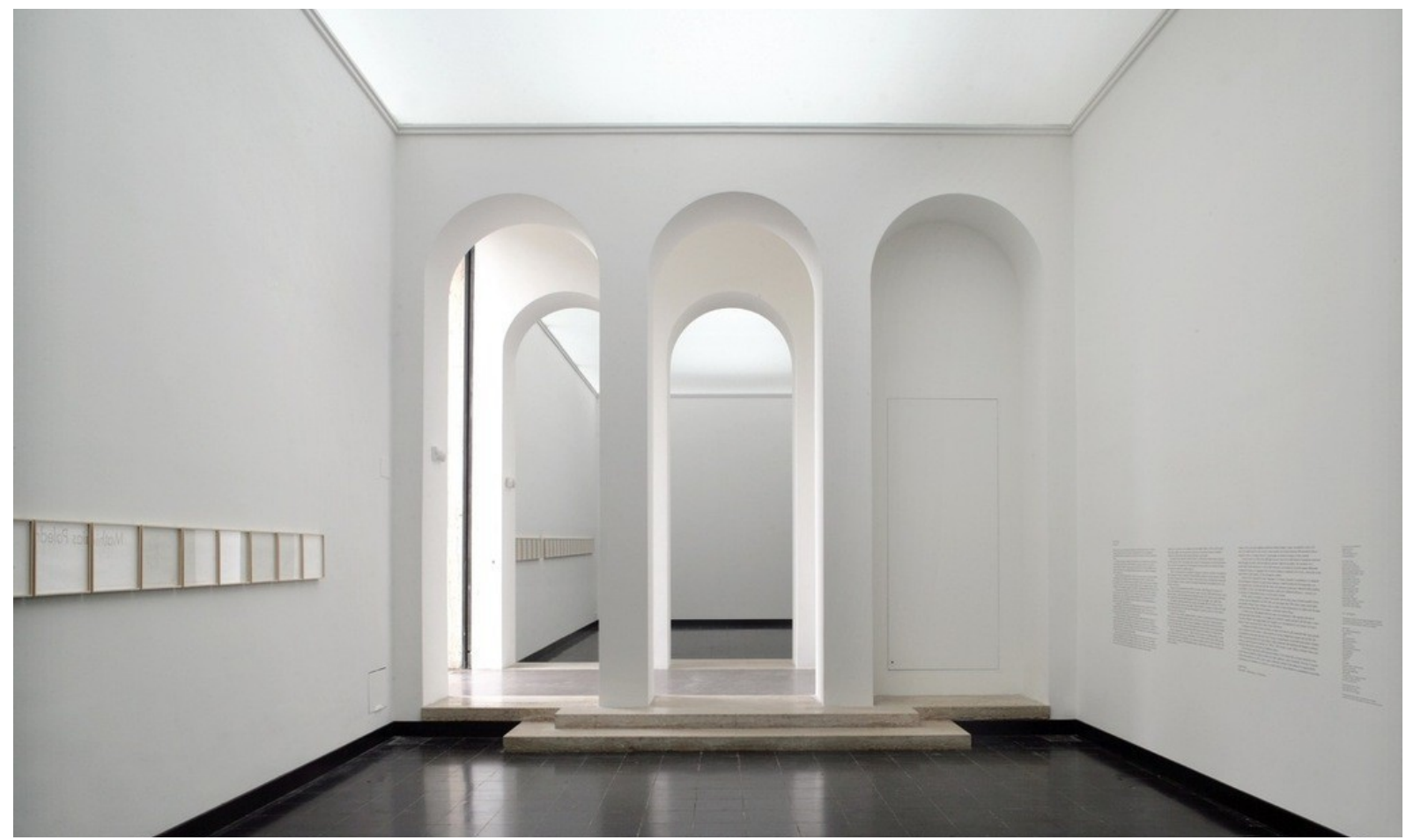

Vista da instalação de Mathias Poledna, Pavilhão austríaco, 55ª Exibição Internacional de Arte, La Biennale di Venezia, 2013 Foto: Divulgação/Daniele Resini

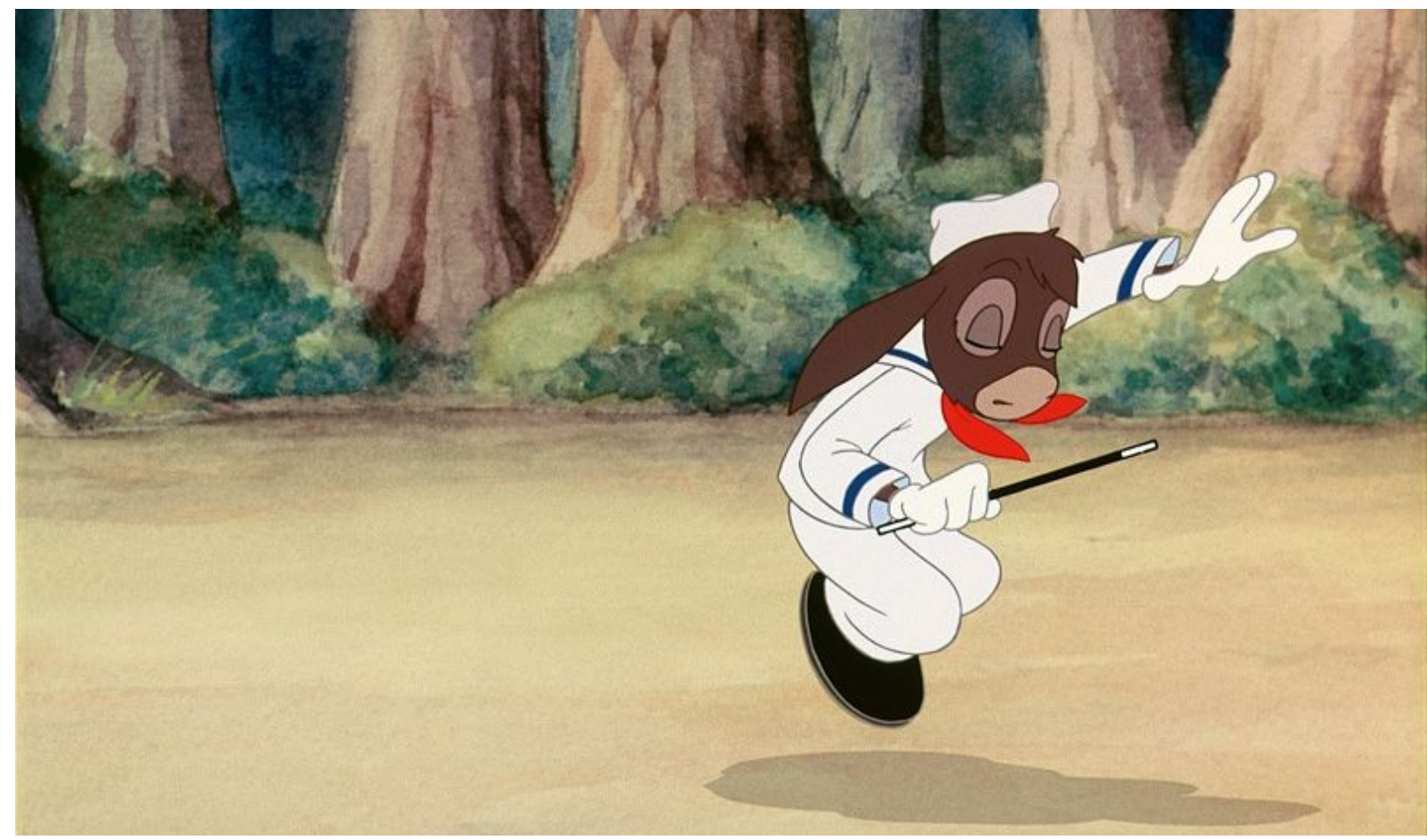

Mathias Poledna, Imitation of Life, 2013 (Pal), filme em 35mm, 3:00 min. Créditos: Divulgação/Mathias Poledna; Galerie Meyer Kainer, Vienna; Galerie Buchholz, Cologne/Berlin; Richard Telles Fine Art, Los Angeles. 
No entanto, embora o estilo remetesse ao universo dos desenhos animados da Disney dos anos 1940, tanto o melancólico jumento quanto o storyboard da animação haviam sido elaborados por uma equipe coordenada por Poledna. Era um desenho bem produzido, que poderia ter sido criado décadas atrás pela própria Disney. Mas, a despeito da pilhagem daquele vocabulário imagético das animações da Disney, executada sem qualquer traço de ironia, a obra exposta na sala poderia ser descrita como "autêntica", pois havia sido criada por um artista visual austríaco em 2013. Ao sair da sala de projeção, o espectador deparava-se com um cartaz afixado na parede que detalhava os créditos da obra. Descobria-se então que, para a realização daqueles três minutos de Imitação da vida, a equipe coordenada por Poledna havia adotado as mesmas técnicas de animação à mão dos anos 1930 (hoje superadas pela computação gráfica comercial), havia mobilizado uma complexa divisão do trabalho, exigindo recursos consideráveis, que hoje seriam totalmente descabidos. Ao lado do cartaz exposto na saída da sala de projeção, um conjunto de layouts, esboços, telas de fundo pintadas a guache, células de animação estavam afixados, comprovando materialmente o aspecto analógico da produção. Para a gravação da faixa sonora, por exemplo, Poledna havia contratado uma orquestra completa (o que também seria desnecessário em função dos recursos computacionais hoje disponíveis). Os nomes dos músicos apareciam igualmente no cartaz na saída da sala. Como que incorporados ao efeito da obra-instalação, o conjunto de rascunhos e os créditos pareciam destacar tanto o aspecto artesanal (desenhos pintados à mão) quanto industrial (a complexa divisão do trabalho) do processo de criação. Demonstravam o quanto, para produzir uma animação de três minutos, era exigido em termos de recursos e organização, recursos superiores inclusive aos de boa parte das obras apresentadas na própria Bienal.

Chamava a atenção o fato de que Imitação da vida, instalação cujo conteúdo tinha uma ambição expressiva praticamente nula, era a única obra do pavilhão austríaco. Estava referendada pela curadoria de uma das exposições mais importantes do circuito da arte contemporânea. Precisamente pela linguagem pasteurizada e inofensiva, parecia ocupar um espaço no qual, a rigor, não estaria autorizada a entrar: a Bienal de Veneza, templo histórico da cultura de vanguarda, espaço institucionalmente demarcado para o "questionamento crítico" de nossos esquemas de percepção. Nesse contexto, tratava-se de uma obra estranha; um estranhamento que não procedia do resultado vocabular da animação, mas do seu lugar de exibição assim como dos imensos recursos mobilizados para sua realização. 


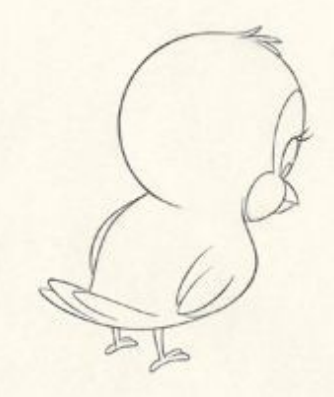

Mathias Poledna, Imitation of Life (Vorzeichnung), 2013, desenho de produção, lápis sobre papel de animação, approx. 30.5 x 42 cm. Créditos: Divulgação/ Mathias Poledna.

Quanto ao lugar de exibição, a provocação da obra de Poledna lembrava em certa medida os ready-mades de Duchamp ou as Brillo Boxes de Andy Warhol: o desenho seria um ready-made feito de materiais visuais gastos, de sedimentos de uma linguagemmercadoria proeminente da indústria cultural (os desenhos da Disney), ao qual seria atribuída, no contexto da Bienal, a dignidade de "obra de arte". Como o urinol de porcelana ou as caixas de sabão em pó devidamente dispostas em museus, Imitação da vida deixava a condição imediata de mercadoria da cultura de entretenimento. Era exibido no circuito da dita arte séria, espaço supostamente comprometido com o gesto modernista da "autenticidade". Havia uma astúcia em Poledna ao não deplorar ou ridicularizar a linguagemmercadoria dos desenhos animados, como seria talvez esperado da paródia, da ironia de caráter modernista. Poledna aceitava a linguagem mercantilizada de maneira reverente, sem confrontação. Porém, a exposição de sua obra na Bienal, de sua animação trivial que apenas obedecia a um padrão gasto da indústria do entretenimento, acabava produzindo 
curiosamente um efeito de obra não-orgânica, fragmentária. Pois em função do lugar que Ihe assegurava o efeito institucional de "obra de arte", a instalação parecia criticar e escarnecer toda noção resiliente de "arte séria". Dito de outro modo, apresentava-se como obra de arte que recusava artisticamente a imagem de obra de arte.

É verdade que esse tipo de procedimento, no fundo, deixou de causar estranhamento, pelo menos desde que a própria arte institucional passou a assimilar o princípio vanguardista do choque e da denegação de sentido como um de seus procedimentos rotineiros ${ }^{19}$. O que um dia chegou a ser escárnio, provocação contra a instituição arte, hoje é validado e mesmo estimulado no circuito de galerias e exposições internacionais; de resto, as próprias exposições têm abandonado a prerrogativa de se estabelecerem como espaços de formação (conforme a ideologia iluminista que deu origem os museus) para se oferecer como espaços destinados à distração e ao entretenimento, cedendo cada vez mais à lógica do espetáculo ${ }^{20}$. Portanto, à primeira vista, a obra de Poledna seria mais uma confirmação, entre tantas outras, da espetacularização do belo, do pastiche e do kitsch que marcariam o fim da era do "estilo do sublime". Seria mais um exemplo irrelevante da colonização da realidade por formas visuais gratificantes, suscetíveis à mercantilização, que constituiriam a dominante cultural do capitalismo tardio. Portanto, pensar essa obra em termos da ideia de sublime seria, de saída, um erro histórico.

Contudo, a intenção da obra parecia estar também além de seu resultado vocabular, do conteúdo banal da animação, e além de seu lugar de exposição. O segundo elemento de provocação da obra que se destacava era o fato de mobilizar imensos recursos para sua realização. Ou seja, a realidade para a qual Poledna, um artista historicamente avisado, realmente queria chamar a atenção era o conjunto de rascunhos e os créditos que evidenciavam a necessidade de uma complexa organização de trabalho, ainda que atualmente desnecessária. Um efeito de autenticidade da obra parecia irromper da "denúncia" desse nexo estrutural entre o imaginário naturalista dos desenhos feéricos da Disney e a organização industrial das atividades para sua criação: a contradição entre a simplicidade da linguagem do desenho e a complexidade de um trabalho segmentado e com alto grau de especialização fazia parte do próprio efeito da obra.

Ao se defrontar no interior de um pavilhão da Bienal com uma arte que deixou de ser arte e que mobiliza um aparato industrial considerável, o espectador se pergunta se não

19 Ver nesse sentido o estudo já mencionado: BÜRGER, Teoria da vanguarda, principalmente a seção 3. 20 Cf. "A história da arte no novo museu: a busca por uma fisionomia própria" in BELTING, O fim da história da arte, São Paulo: Cosac Naify, 2016. 
estaria diante de uma manifestação que se revolta contra seu próprio conceito, contra sua pretensão à autenticidade - mas uma manifestação que, nesse mesmo gesto, afirma uma autenticidade de outra ordem. Dito de outra maneira, o espectador se pergunta se não estaria, afinal, conforme a própria concepção de Jameson, diante da essência de um sublime esteticamente considerado ${ }^{21}$. Certamente, não se tratava, na animação, da força de objetos naturais ${ }^{22}$, nem do impulso modernista dado a partir de um estilema. Contudo, a obra-instalação de Poledna - com seus créditos que faziam perceber como são pequenos os recursos aplicados para obras de arte ditas de "vanguarda", quando comparados aos custos de uma simples animação - mostraria, do interior da arte institucionalizada, "aquilo em comparação com o qual tudo o mais é pequeno": a força da indústria do entretenimento (ou da "cultura pós-moderna") a ponto de se transformar em segunda natureza ${ }^{23}$. Pois ali estaria revelado o quanto a linguagem-mercadoria dos desenhos da Disney conformou nosso imaginário, a ponto de termos dificuldade de nos distanciar de sua iconografia convencional, de sua vida imitada, da animação criada a partir de ritmos fixos, esquemas rotineiros e industrializados. Dificilmente percebemos o quanto a imagem festiva da natureza dos desenhos animado configura uma máscara mortuária da natureza.

Ao contrário daquela natureza descrita na terceira crítica de Kant capaz de provocar o sentimento do sublime, o espetáculo da segunda natureza, animada pelos desenhos, não possui força alguma. Mas não seria precisamente a linguagem cintilante da animação, máscara mortuária da natureza, que remeteria a esse "outro poder que desafia nossas forças"24? Ou seja, se, em um primeiro momento, o espectador constatava a subordinação quase instintiva de sua fantasia ao esquematismo da indústria cultural e à sua natureza mortificada ${ }^{25}$, em um segundo momento, ao deslocar sua atenção para sua complexidade

21 "O modernismo aspira ao sublime como sua essência, ou seja, na medida em que deseja atingir o absoluto, acredita que para ser arte, arte deve estar além da arte." (JAMESON, "Fim da arte" ou "fim da história" ?, p. 84). 22 "Rochedos audazes ameaçadores, nuvens carregadas no céu, avançando com relâmpagos, vulcões, furacões, oceano revolto, queda d'água tornam a nossa capacidade de resistência de uma pequenez insignificante em comparação com seu poder." (KANT, Crítica da faculdade do juízo, p. 107).

23 "O pós-modernismo é o que se tem quando o processo de modernização está completo e a natureza se foi para sempre... 'cultura' se tornou verdadeira 'segunda natureza'” (JAMESON, Pós-modernismo. A lógica cultural do capitalismo tardio, p. 13).

24 "Tudo o que suscita este sentimento em nós, a que pertence o poder da natureza que desafia nossas forças, chama-se sublime" (KANT, Crítica da faculdade do juízo, p. 110) Valeria lembrar nesse ponto a noção de choque em Benjamin, como marca da situação de impotência do indivíduo diante das forças da civilização em seu estágio técnico-industrial avançado (Cf. BENJAMIN, Obras Escolhidas - Vol. III - Charles Baudelaire um Lírico no Auge do Capitalismo, São Paulo: Brasiliense, 1989).

25 Para Adorno e Horkheimer, "a função que o esquematismo kantiano ainda atribuía ao sujeito, a saber, referir de antemão a multiplicidade sensível aos conceitos fundamentais, é tomada ao sujeito pela indústria (cultural)" (ADORNO; HORKHEIMER, Dialética do esclarecimento - fragmentos filosóficos, Rio de Janeiro: Jorge Zahar, 1985, p. 117). Os autores referem-se, neste capítulo de Dialética do esclarecimento, à "atrofia da imaginação", em sentido kantiano, ocasionada pela indústria cultural. 
industrial e refletir sobre tal subordinação, ele não descobriria uma intencionalidade crítica presente na obra e, com ela, uma incipiente e autêntica resistência da consciência a esse estado de coisas? Uma nova torção do sublime esteticamente considerado?

Em suas Minima Moralia, Adorno ponderava (contra qualquer periodização historicista) que a "modernidade é uma categoria qualitativa, de modo algum cronológica. Por menos que aceite a formulação abstrata, ainda necessita da renúncia à superficialidade convencional, à aparência de harmonia, à ordem fortalecida pela mera figuração" ${ }^{26}$. Nesse sentido, para Adorno, a categoria de sublime, associada à consciência crítica do moderno, permanece como desejo de renúncia à superficialidade, à aparência de harmonia, ao interesse imediato dos sentidos. Quem sabe Imitação da vida - ao reconhecer como pertencente a seu efeito de obra tanto o lugar de exibição quanto o desvelamento de seu processo de criação (mediante a exposição dos créditos e a revelação de seus bastidores pouco artesanais) - estivesse exibindo um procedimento, de teor modernista, de transformar a falsidade da beleza kitsch e de seu resultado superficial em um modelo crítico à aparência de harmonia. Se Hans Belting chegou a sugerir que o "fim da arte" foi na maioria das vezes uma palavra de ordem para a proclamação de uma nova arte, ou melhor, a oportunidade esperada para se reescrever a história da arte precedente ${ }^{27}$, então pela estreita abertura à resistência que a categoria de sublime ainda hoje talvez ofereça, poderíamos entrever hegelianamente - a continuidade de uma verdade histórica e inquietante do espírito.

26 ADORNO, Minima Moralia: reflexões a partir da vida lesada, Rio de Janeiro: Azougue Editorial, 2008. Aforismo 140, Culminação dos tempos.

27 Cf. BELTING, O fim da história da arte, p. 201. 


\section{Referências bibliográficas}

ADORNO, Theodor W. Minima Moralia: reflexões a partir da vida lesada. Trad. Gabriel Cohn. Rio de Janeiro: Azougue Editorial, 2008.

Teoria estética. Trad. Artur Morão. Lisboa: Edições 70, 2008.

ADORNO, Theodor W.; HORKHEIMER, Max. Dialética do esclarecimento - fragmentos filosóficos. Trad. Guido Antonio de Almeida. Rio de Janeiro: Jorge Zahar, 1985.

ARANTES, Otília B. Fiori; ARANTES, Paulo Eduardo. Um ponto cego no projeto moderno de Jürgen Habermas. São Paulo: Brasiliense, 1995.

BELTING, Hans. O fim da história da arte. Trad. Rodnei Nascimento. São Paulo: Cosac Naify, 2016.

BENJAMIN, Walter. Obras Escolhidas - Vol. III - Charles Baudelaire um Lírico no Auge do Capitalismo. São Paulo: Brasiliense, 1989.

BÜRGER, Peter. Teoria da vanguarda. Trad. José Pedro Antunes. São Paulo: Cosac Naify, 2008.

CACHOPO, João Pedro. Verdade e enigma - Ensaio sobre o pensamento estético de Adorno. Lisboa: Edições Vendaval, 2013.

HABERMAS, Jürgen. O discurso filosófico da modernidade. Trad. Luiz Repa; Rodnei Nascimento. São Paulo: Martins Fontes, 2000.

JAMESON, Fredric. "Fim da arte" ou "fim da história" ? In: A cultura do dinheiro. Trad. Maria Elisa Cevasco; Marcos César de Paula Soares. Petrópolis: Vozes, 2001.

JAMESON, Fredric. Pós-modernismo. A lógica cultural do capitalismo tardio. Trad. Maria Elisa Cevasco. São Paulo: Ática, 2006.

KANT, Immanuel. Crítica da faculdade do juízo. Trad. Valerio Rohden; Antonio Marques. Rio de Janeiro: Forense Universitária, 2008.

LYOTARD, Jean-François. O inumano - Considerações sobre o tempo. Trad. Ana Cristina Seabra; Elisabete Alexandre. Lisboa: Editorial Estampa, 1997.

SCHILLER, Friedrich. Do sublime ao trágico. Belo Horizonte: Autêntica, 2016. 